\title{
Editorial
}

\section{History of Thyroid Surgery}

The dark age; Shoe laces, sea weed

Thyroid surgery has it root over one millennium ago. It spans the length and breath of surgery itself, harking back through thousands of years and now fanning out through modern surgical specialties.

First thyroid surgery was done by Albucasis in $952 \mathrm{AD} .{ }^{1}$ Although there have been earlier reports of similar surgeries, their validity has not been warranted. Indeed Ruggiere Frugadi (pre A 1140-1195) is often credited as performing first thyroid surgery in 1170 , using bootlaces as setons to ligate and transfix a pedunculated goiter, allowing it to slough off. ${ }^{2}$

In 1511, during the Italian Renaissance, Leonardo Da Vinci was the first person to draw the anatomical structure of the thyroid gland but misinterpreted it,s function. In the $16^{\text {th }}$ century Andreus Vesalius described first the thyroid structure. But treatment of goiter started in China around $2700 \mathrm{BC}$, and in as early as $1600 \mathrm{BC}$, the Chinese used burnt sponge and seaweed to treat goitre. ${ }^{3}$

The true beginnings: Foolhardy performances and horrid butchery: Despite early attempts thyroid surgery did not progress for several centuries. Early attempts by Benjamin Gooch(1708-1776), resulted in fatal haemorrhage. During the French revolution Pierre Joseph Desault (1744-1795) performed a successful thyroidectomy in a 20 year old women. ${ }^{4}$ Surgeon like Dupuytren in1808, Willium Blizard in 1811 or Henry Earle in 1823 followed him closely. But still it passed through a series of crests and troughs over the ages as its proponents and opponents held sway in the medical field over different periods of time. However Halsted in his operative history of goiter mentioned $40 \%$ mortality following thyroid surgery due to haemorrhage, asphyxia, hospital gangrene and air embolism. ${ }^{5}$ And At one point of history, thyroid surgery was considered such a dreaded operation with a definite grim outcome that surgeons were fearful in performing it at all and French academy of medicine banned thyroid suegery. Johann Dieffenbach(1792-1847) who after repeated try mentioned it as foolhardy performances and thankless job. ${ }^{6}$ Even the great American Surgeon Samuel Gross(1805-1884) described thyroid surgery as horrid butchery and discouraged every surgeon not to engage in it. ${ }^{7}$

The new dawn: Three great advances and the fathers of thyroid surgery.
Thyroid surgery started coming out of its doldrums in the middle of the nineteenth century. This was due to introduction of anaesthesia, infection prophylaxis and better haemostasis. Oliver Wendell Holmes coined the term anaesthesia ;Crawford W Long of Georgia used ether as the anaesthetic agent for the first time in 1846. Three years later Nikolai Piringoff performed a successful thyroidectomy using ether anaesthesia in St Petersburg. ${ }^{6}$.

Surgery progressed further with introduction of carbolic acid as antisepsis by Joseph Lister of Glasgow in $1867 .{ }^{8}$ The introduction of stem sterilization of instruments by Ernst von Bergmann in 1886 and intraoperative antisepsis with cap and gown by Gustav Neubar in 1885 reduced the incidence of infection significantly in the post operative period. ${ }^{9}$ In 1874 , Spencer Wells and Jules Pear reached a landmark in surgery by introducing the first effective haemostatic forceps. With all these three advances, the surgical stage was well set for the advent of the most skilled surgeons of the nineteenth century.

These three developments prepared the way for Albert Theodor Billroth (1829-1894) the most famous surgeon of his day performed 36 thyroidectomies experiencing 16 deaths, in Zurich and Vienna. ${ }^{10}$ With the use of newer methods of antisepsis and haemostasis in between 1877 to 1881 , Billroth performed 48 thyroidectomies and was able to decrease the mortality to $8.3 \%$.

However, Biliroth,s greatest student Theodor Kocher (1841-1917) carried forward the baton of thyroid surgery from his teacher and truly considered the Father of thyroid surgery. In 1872 Kocher was appointed to the chair of Surgery in Berne. His knowledge of anatomy and circulation aided his meticulous dissection technique and adopted the classical collar incision that bears his name in 1890 . During his first 10 years in Berne he had done 101 thyroidectomies with $2.4 \%$ mortality and by 1895 his mortality rate reduced to $1 \%$. In 1909 , Kocher won the Nobel Prize for his work in physiology, pathology and surgery on thyroid gland. ${ }^{11}$

Kocher went on to train Willium Halsted (1794-1878), an American surgeon who popularized the use of haemostatic forceps and parathyroid preservation. In 1896 ,Vassale and Generalim demonstrated that loss of parathyroid function may cause tetany in animal. ${ }^{12}$ This gave an opportunity for some of Billroth,s pupils to work on it . 
Anton wolfer of Graz described tetany in details in 1886. Jan Mikulicz Radecki suggested preservation of posterior aspect of both thyroid lobes to prevent tetany in 1882 . Another serious complication following thyroid surgery was recurrent laryngeal nerve injury which were not diagnosed till the introduction of mirror examination of the larynx by Manuel Garcia, a Spanish singer in 1851 .

As the years advanced toxic goiters posed a new challenge for the surgeons. In 1905 Frank Hartley advocated resecting one thyroid lobe and some portion of the opposite lobe for the treatment of hyperthyroid patients. ${ }^{13}$ Thomas Dunhill (1876-1957) followed Hartley,s theory. and in 1912 published a paper of 380 thyrotoxic patients underwent surgery with a mortality of about $1 \%$. In this regards Kocher practiced initial ligation of the thyroid arteries. George Crile (1864-1943) and Charles Mayo (18651939) practiced unilateral or bilateral pole ligation prior to partial thyroidectomy. ${ }^{14}$ Frank Lahey (1880-1953) instituted basal metabolic rate as pre operative marker for hyperthyroidism. He adopted Mayo,s strap division advice, suggested identification of recurrent laryngeal nerve, and parathyroid auto implantation into the sternocleidomastoid muscle.

In 1923 Henry Plummer (1874-1936) published results of 600 thyrotoxic patients treated with Lugol,s iodine preoperatively before passing them on to Mayo for surgery.This approach reduced the mortality rate from 4 to $1 \%{ }^{15}$ The introduction of radioiodine in Boston and Berkley for the treatment of thyroid cancer and grave,s disease in 1942 by Means,Evans and Hertz improved survival and cure rate of toxic patients. A year later, in 1943 antithyroid drug thiouracil created and advocated by Edwin Bennett astwood(1909-1976). 20 years later beta blocker was introduced for the treatment of toxic patients in 1965. Introduction of fine needle cytology in 1952 by Soderstorm improved the diagnostic accuracy of goiter. ${ }^{8}$

\section{The modern age}

The history of thyroid surgery belongs to general surgery, but over the past three decades it has been seen a shift towards otolaryngologist and head neck surgeons working together with endocrine surgeons. ${ }^{4}$ With the advent of thyroid specialists, the operative technique has undergone significant refinement and subsequent changes in the extent of surgery performed. Subtotal thyroidectomy has been largely abandoned now and the current valid operation is total lobectomy or total thyroidectomy with near total acceptable to preserve a nerve at risk.
The prognostic factors and risk group analysis in thyroid cancers were very well defined by Hay from the Mayo clinic and Cadey from the Lahey clinic. While Kocher,s classic 8-10 $\mathrm{cm}$ transverse incision was the standard for almost a century which has been now replaced by small incision of 3-6 cm. Even to avoid neck scar mark new technique of minimally invasive video assisted thyroidectomy(MIVAT) has been introduced by Paulo Mucozi in $1997^{16}$, with access from the axilla ${ }^{17}$, breast $^{18}$. Further advancement of thyroid surgery was achieved by Chung of South Korea introducing Robot assisted thyroid surgery. ${ }^{4}$ Not only the surgical technique but there is also advancement of surgical tools like harmonic scalpel, new suture materials.

In conclusion thyroid surgery has indeed passed through a long and arduous path from failure or even death to the most safest operation with the efforts of brave pioneers of surgery and how they advanced the surgical treatment from the dark ages to the modern era. And to finish where it all began, we return to Billroth ; Only a man who is familiar with the art and science of the past is competent to aid in it,s progress in the future". ${ }^{19}$

[J Shaheed Suhrawardy Med Coll 2018; 10(2): 62-64] DOI: https://doi.org/10.3329/jssmc.v10i2.41158

\section{Professor MA Matin FRCS}

Professor of Otolaryngology, Shaheed Suhrawardy Medical College Hospital

\section{References}

1. Haddad FS. Abulcasis.Abbottempo.1968: 3:22-25

2. Corner G. The rise of medicine at salerno in the twelfth century.Newyork: P.B. Hoeber; 1931

3. Welbourn R B. The history of endocrine surgery.Newyork: Praeger; 1990

4. Watkinson J C, Clarke R W. Scott-Brown,s otorhinolaryngology Head and Neck Surgery. History of thyroid and parathyroid surgery. CRC Press NW. $8^{\text {th }}$ ed.Vol 1 p 597-602.

5. Halsted WS. The operative history of goiter: the author,s operation. John Hopkins Hosp Rep 1920;19:71-257.

6. Diffenbach JF. Die operative Chirurgie II. Leipzig: FA Brockhaus; 1848.p.331.

7. Gross SD. A system of surgery, vol II.4. Philadelphia; H.C.Lea; 1886 .

8. Lister J. The collected papers of Joseph Baron Lister. Oxford; Clarendon Press; 1909.

9. Garrison FH. An introduction to the history of medicine.4.Philadelphia; WB Saunders Co;1929. 
10. Becker WF. Presidential address: pioneers in thyroid surgery. Ann Surg.1977; 185:493-504.doi:10.1097/00000658197705000-00001.

11. Fortuny JV, Guigard at al. Surgery of the thyroid ;recent developments and perspective.Swiss Med Wkly.2015; 145:w 14144

12. Harwick RD. Our legacy of thyroid surgery.Am J Surg. 1988;156:230-234.

13. Hartley F. Thyroidectomy for exophthalmic goiter. Ann Surg $.1905 ; 42: 33-48$.

14. Mayo $\mathrm{CH}$. Ligation and partial thyroidectomy for hyperthyroidism. In : Melish MH, editor. Collected papers by the staff of St Mary,s Hospital, Mayo Clinic;1910.
15. Plummer HS. Results of administtering iodine to patients having exophthalming goiter. JAMA.1923;80:1955.

16. Miccoli P, Berti P, Frustaci GI et al.video-assisted thyroidectomy;indications and results.Langenbecks Arch Surg 2006;391(2):68-71.

17. Inabnet WB III, Gagner M.Endoscopic thyroidectomy.J Otolaryngol.2001;30:41-42.

18. Takami H,Ikeda Y.Minimally invasive thyroidectomy.Aust NZ J Surg.2002;72:841-842.

19. Billroth T. Die Allegmeine chirurgischen pathologie und therapie in Funfzig voriesungen. Berlin: G Reimer;1863. 